\title{
Tuberculosis recurrence in smear-positive patients cured under DOTS in southern Ethiopia: retrospective cohort study
} Daniel G Datiko*1,2 and Bernt Lindtjørn ${ }^{1}$

\author{
Address: ${ }^{1}$ Centre for International Health, University of Bergen, Overlege Danielsens Hus, Årstadveien 21, 5009 Bergen, Norway and ${ }^{2}$ Southern \\ Nations, Nationalities, and Peoples' Regional Health Bureau, PO Box 149, Hawassa, Ethiopia \\ Email: Daniel G Datiko* - danieljohn42@yahoo.com; Bernt Lindtjørn - bernt.lindtjørn@cih.uib.no \\ * Corresponding author \\ Published: 18 September 2009 \\ BMC Public Health 2009, 9:348 doi:10.1 186/147|-2458-9-348 \\ This article is available from: http://www.biomedcentral.com/I47I-2458/9/348 \\ (c) 2009 Datiko and Lindtjørn; licensee BioMed Central Ltd. \\ This is an Open Access article distributed under the terms of the Creative Commons Attribution License (http://creativecommons.org/licenses/by/2.0), \\ which permits unrestricted use, distribution, and reproduction in any medium, provided the original work is properly cited. \\ Received: 13 January 2009 \\ Accepted: 18 September 2009
}

\begin{abstract}
Background: Decentralization of DOTS has increased the number of cured smear-positive tuberculosis (TB) patients. However, the rate of recurrence has increased mainly due to HIV infection. Recurrence rate could be taken as an important measure of long-term success of TB treatment. We aimed to find out the rate of recurrence in smear-positive patients cured under DOTS in southern Ethiopia.
\end{abstract}

Methods: We did a retrospective cohort study on cured smear-positive TB patients who were treated from 1998 to 2006. Recurrence of smear-positive TB was used as an outcome measure. Person-years of observation (PYO) were calculated per 100 PYO from the date of cure to date of interview. Kaplan-Meier and Cox-regression methods were used to determine the survival and the hazard ratio (HR).

Results: 368 cured smear-positive TB patients which were followed for 1463 person-years. Of these, 187 patients $(50.8 \%)$ were men, 277 patients $(75.5 \%)$ were married, 157 (44.2\%) were illiterate, and 152 patients (4I.3\%) were farmers. 15 of 368 smear-positive patients had recurrence. The rate of recurrence was I per 100 PYO ( 0.01 per annum). Recurrence was not associated with age, sex, occupation, marital status and level of education.

Conclusion: High recurrence rate occurred among smear-positive patients cured under DOTS. Further studies are required to identify factors contributing to high recurrence rates to improve disease free survival of TB patients after treatment.

\section{Background}

The World Health Organization (WHO) recommends directly observed treatment short-course (DOTS) to control tuberculosis (TB). It advocates early case detection and prompt treatment to ensure long-term success by reducing transmission, recurrence (relapse or reinfection) and death [1].
Decentralized DOTS implementation has increased the number of successfully treated TB patients [2-5]. However, in some countries, the incidence of TB has increased, as has the risk of defaulting, failure, death and recurrence, mainly because of the HIV epidemic [6,7]. Therefore, recurrence and death in successfully treated TB patients could be taken as an important measure of the efficacy of 
TB treatment. However, there are no routines in monitoring TB patients after completing treatment.

Post-treatment studies reported high recurrence rate in TB patients (36\%) after 22 months of follow-up [8]. The recurrence rates were high among patients infected with HIV infected and multidrug resistant (MDR) TB (cases with strains resistant at least to isoniazid and rifampicin) [8-10]. This may increase $\mathrm{TB}$ incidence and reduce the treatment success $[11,12]$.

In Ethiopia, the success of TB control is affected by the shortage of health workers to conduct case finding and treatment supervision [4]. In such settings, poor treatment adherence and extended treatment regimen could compromise the long-term efficacy of TB treatment by increasing the rate of recurrence, transmission of infection and emergence of drug resistance [13].

To our knowledge, no follow-up study has been conducted in Ethiopia to determine recurrence rates in cured smear-positive TB patients. The aim of the study was to find out the rate of recurrence through community based follow-up of smear-positive TB patients cured under DOTS.

\section{Methods}

\section{Study area and population}

We did this study in Dale and Wonsho districts of Sidama zone in the southern Ethiopia (Figure 1). It is a densely populated agrarian community (with a population of 296, 811). DOTS was started in 1996 [14] and six health facilities were providing TB service in the study area. Trained general health workers administer directly observed treatment. Standard recording and reporting formats were used in the health facilities and the districts. District TB programme experts regularly checked the completeness and accuracy of the recording in the unit TB register. The estimated prevalence of TB in the study area was 643 per $10^{5}$ population; and the incidence of smear-positive cases was 168 per $10^{5}$ population for 2006 [4]. The case detection, cure and treatment success rates were $41 \%$, $58 \%$ and $76 \%$ respectively. The sputum conversion rate at second month of follow-up was $83 \%$ (unpublished report from the study area).

\section{Study design}

This was a retrospective cohort study based on TB patients that were registered in unit TB registers in the health facilities providing DOTS. We enrolled new and retreatment cases that were reported cured from 1998 to 2006 through house-to-house visit.

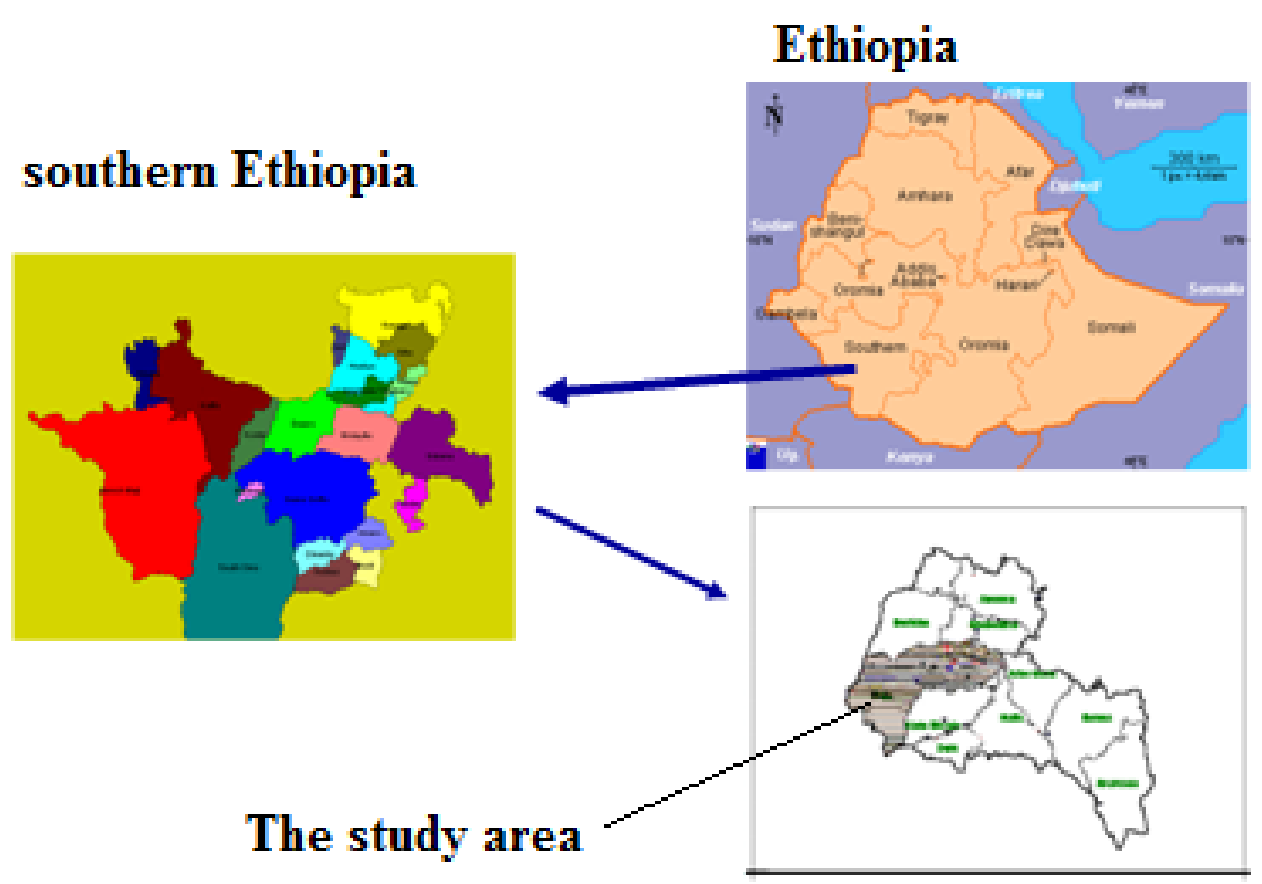

\section{Sidama zone}

\section{Figure I}

Map of the study area in Sidama zone in the southern Ethiopia. 


\section{Case definition, treatment duration and outcome}

TB patients who had productive cough for two weeks or more with at least two positive sputum smears or one positive smear and $\mathrm{x}$-ray findings consistent with active PTB were classified as smear-positive pulmonary TB cases.

TB patients received two months intensive phase and six months continuation phase treatment. Follow-up sputum examination was done at the end of $2^{\text {nd }}, 5^{\text {th }}$ and $7^{\text {th }}$ months of treatment. A smear-positive TB patient who had negative sputum smear result in the last month of treatment and on at least one previous occasion $\left(2^{\text {nd }}\right.$ or $5^{\text {th }}$ month) was reported as cured. The term recurrence was used to indicate rediagnosis of smear-positive $\mathrm{TB}$ in patients who were reported cured [8].

\section{Data collection}

From unit TB register in health institutions in the two districts, we obtained the list of smear-positive TB patients who were declared cured from 1998 to 2006. We collected information about unit register number, name, age, sex, address, TB category, smear result and the treatment outcome. The data was crosschecked with the district TB register that contained the list of the patients treated in the health institutions in the districts. Trained health extension workers conducted house-to-house visits, and collected data from the TB patients or their households. They collected the information if the TB patient were alive, had symptoms of TB and registered the date of the interview using structured questionnaire. The data collection was done from September 2007 to February 2008. HIV results were not available for TB patients enrolled in our study.

\section{Data analysis}

We used SPSS 14 for Windows for data entry and analysis. We described the patients by age, sex, TB category, marital status, level of education and occupation. The outcome measure was recurrence of TB. Person-years of observation (PYO) were calculated from the date of cure to date of interview.

We used the Kaplan-Meier method to find out the eventfree survival and the log-rank test for the statistical significance. Cox-regression method was used to determine the hazard ratio (HR) and 95\% Confidence interval (95\%CI). Recurrence rate was calculated as the number of recurrences per 100 PYO. P-value less than 0.05 was considered significant.

\section{Ethical clearance}

The Ethical Review Committee of the Regional Health Bureau approved this study. After explaining the aim of the study, we obtained informed consent from the study participants or head of the household. Patients with recent history of cough and other symptoms suggestive of
TB were advised to visit health posts for sputum collection by health extension workers or to visit diagnostic health institutions for examination.

\section{Results}

Of the 397 smear-positive TB patients registered, 368 $(92.7 \%)$ were followed. Incomplete information was obtained for 29 (7.3\%) of which $8(2.0 \%)$ had moved to other districts. However, no difference was observed by age, sex, and TB category compared o the patients we enrolled.

Of the 368 smear-positive TB patients which were followed, 187 patients (50.8\%) were men, 277 patients (75.5\%) were married, 157 (44.2\%) were illiterate, and 152 patients $(41.3 \%)$ were farmers (Table 1$) .368$ cured smear-positive TB patients were followed for 1463 person-years. 15 of 368 smear-positive patients had recurrence. The mean (median) duration of follow-up was 3.87 (4.0) years. The rate of recurrence was 1 per 100 PYO (0.01 per annum). Recurrence was not associated with age, sex, occupation, marital status and level of education (Table 2).

\section{Discussion}

The estimated recurrence rate in our study area was 1 per 100 PYO. This could be explained by HIV infection, MDR $\mathrm{TB}$, reinfection due to high $\mathrm{TB}$ burden and inadequate treatment supervision and patient follow-up.

HIV infection increases the risk of infection, reinfection, recurrence and death. It also increased the workload by fuelling TB epidemic and affected the performance of TB programme [6]. In southern Ethiopia, the prevalence of HIV infection in the general population and TB patients was $3.8 \%$ and $17.5 \%$ respectively [15]. This could be one of the factors to explain the high recurrence rate in our setting. However, the role of HIV in recurrence requires further investigation.

Higher recurrence rates reported elsewhere, $8.6 \%$ in Vietnam after 19 months, $11 \%$ in India after two and half years and 36\% in Kazakhstan after 22 months of followup [16-18] were attributed to MDR TB, poor treatment supervision and inadequate patient follow-up $[8,9,11,12]$. Though the prevalence of MDR TB in Ethiopia was believed to be low (1.6\% in new and $12 \%$ in previously treated $\mathrm{TB}$ cases ), 50\% resistance to one or more drugs in re-treatment cases was reported) [19]. Similarly $7.7 \%$ resistance to at least one TB drug was reported from our study area [20]. This may also be one of the factors to explain the high recurrence rate in our setting.

Moreover, factors that affect the performance of TB programme (poor treatment supervision and failure to do fol- 
Table I: Socio-demographic characteristics of cured smearpositive patients in southern Ethiopia from 1998 - 2006

\begin{tabular}{lrr}
\hline Variables & number & Percent (\%) \\
\hline Sex & & \\
$\quad$ Male & 187 & $50.8 \%$ \\
$\quad$ Female & 181 & $49.2 \%$ \\
Marital status & & \\
$\quad$ Single & 90 & $24.5 \%$ \\
Married & 268 & $73.0 \%$ \\
$\quad$ Divorced/widowed & 9 & $2.5 \%$ \\
Missing & 1 & \\
Level of education & & \\
Illiterate & 157 & $44.2 \%$ \\
I - 4 & 57 & $16.1 \%$ \\
$5-8$ & 120 & $33.8 \%$ \\
$9+$ & 21 & $5.9 \%$ \\
Missing & 13 & \\
Occupation & & \\
Student & 64 & $17.4 \%$ \\
Farmer & 152 & $41.3 \%$ \\
Housewife & 35 & $9.5 \%$ \\
Merchant & 16 & $4.3 \%$ \\
$\quad$ Others & 101 & $27.4 \%$ \\
Current status & & \\
New & 364 & $98.9 \%$ \\
Retreatment & 4 & $1.1 \%$ \\
\hline & & \\
\hline
\end{tabular}

low-up sputum examination) and the patients' general condition could increase the recurrence rate. Inadequate treatment supervision, more pronounced during continuation phase when patients receive unsupervised treatment, reduces treatment adherence and increases the risk of treatment failure and MDR TB. This is worsened when the importance of treatment adherence is not well addressed during health education sessions [21]. Addi- tionally, failure to conduct follow-up sputum examination reduces the chance of detecting failure cases (smearpositive at $5^{\text {th }}$ or $7^{\text {th }}$ month) without affecting the number of patients that complete treatment under DOTS. Thus, in routine practice where cure is based on smear microscopy, treatment failure can be missed.

The limitation of the study were using sputum microscopy for the diagnosis of recurrence in smear-positive patients that may have underestimated the rates of recurrence and lack of HIV test result to estimate the role of HIV in recurrence.

The significance of this study is more in settings with high $\mathrm{TB}$ and HIV prevalence. In such settings high disease transmission may maintain the burden of TB in the community. Yet, high recurrence rates in cured smear-positive TB patients should alert TB programme managers to identify the risk factors. The performance of TB programme could be improved by addressing factors that affect treatment adherence and increase the risk of MDR TB. TB patients could also benefit from the access to HIV prevention and control measures in high-risk patients to reduce recurrence and improve their long-term survival.

\section{Conclusion}

The rate of recurrence in cured smear-positive TB patients was high in our setting. Further studies are required to identify risk factors for recurrence to improve the disease free survival of cured smear-positive TB patients.

\section{Competing interests}

The authors declare that they have no competing interests.

Table 2: Factors predicting recurrence in cured smear-positive tuberculosis patients in southern Ethiopia from 1998 - 2006

\begin{tabular}{|c|c|c|c|c|c|c|}
\hline \multirow[t]{2}{*}{ Variables } & \multicolumn{2}{|c|}{ Recurrence } & \multirow[t]{2}{*}{ PYO* } & \multirow[t]{2}{*}{ Recurrence rate per I00PYO } & \multirow[t]{2}{*}{ Crude HR $(95 \% \mathrm{Cl})^{\dagger}$} & \multirow[t]{2}{*}{$P$ - value } \\
\hline & Yes & No & & & & \\
\hline \multicolumn{7}{|l|}{ Age (in years) } \\
\hline$<15$ & 0 & 28 & 122 & 0.0 & 1.0 & \\
\hline$\geq 15$ & 14 & 324 & 1330 & 1.1 & $0.0(0.0-170)$ & 0.5 \\
\hline \multicolumn{7}{|l|}{ Sex } \\
\hline Female & 5 & 176 & 710 & 7.0 & 1.0 & \\
\hline Male & 10 & 177 & 753 & 1.3 & I.8 (0.6 - 5.5) & 0.3 \\
\hline \multicolumn{7}{|c|}{ Level of education } \\
\hline Illiterate & 5 & 152 & 629 & 0.8 & 1.0 & \\
\hline Literate & 9 & 189 & 783 & 1.2 & $0.7(0.2-1.9)$ & 0.5 \\
\hline \multicolumn{7}{|l|}{ Marital status } \\
\hline Never married & 1 & 89 & 338 & 0.3 & 1.0 & \\
\hline Married & 14 & 263 & 1118 & 1.3 & $03(0.03-1.9)$ & 0.2 \\
\hline \multicolumn{7}{|l|}{ Occupation } \\
\hline Farmers & 12 & 239 & 997 & 1.2 & 1.0 & \\
\hline Non farmers & 3 & 114 & 466 & 0.6 & $1.9(0.5-6.6)$ & 0.3 \\
\hline
\end{tabular}

* PYO - person-year observation

t HR - hazard ratio, $95 \% \mathrm{Cl}-95 \%$ confidence interval 


\section{Authors' contributions}

DGD supervised data collection. DGD and BL analyzed, interpreted the findings and prepared the drafts. All authors contributed to the final manuscript

\section{Acknowledgements}

The authors acknowledge the contribution made by the TB programme manager, health workers and health extension workers in the Dale and Wonsho districts of Sidama zone. We are also grateful to TB patients who participated in the study.

\section{References}

I. Raviglione MC: The TB epidemic from 1992 to 2002. Tuberculosis (Edinb) 2003, 83(I-3):4-14.

2. Shargie EB, Lindtjorn B: DOTS improves treatment outcomes and service coverage for tuberculosis in South Ethiopia: a retrospective trend analysis. BMC Public Health 2005, 5(I):62

3. Xianyi C, Fengzeng Z, Hongjin D, Liya W, Lixia W, Xin D, Chin DP: The DOTS strategy in China: results and lessons after 10 years. Bull World Health Organ 2002, 80(6):430-436.

4. World Health Organization: Global Tuberculosis Control, surveillance, planning and financing Geneva, Switzerland: World Health Organization; 2008.

5. Dye C, Hosseini M, Watt C: Did we reach the 2005 targets for tuberculosis control? Bull World Health Organ 2007, 85(5):364-369.

6. Maher D, Harries A, Getahun H: Tuberculosis and HIV interaction in sub-Saharan Africa: impact on patients and programmes; implications for policies. Trop Med Int Health 2005, I 0(8):734-742.

7. Harries AD, Dermot, Maher, Stephan, Graham :. In TB/HIV A Clinical Manual Volume 329. 2nd edition. WHO, Switzerland, Geneva; 2004.

8. Cox H, Kebede $Y$, Allamuratova S, Ismailov G, Davletmuratova Z, Byrnes G, Stone C, Niemann S, Rusch-Gerdes S, Blok L, et al.: Tuberculosis recurrence and mortality after successful treatment: impact of drug resistance. PLoS Med 2006, 3( I 0):e384.

9. Kang'ombe $C$, Harries AD, Banda $H$, Nyangulu DS, Whitty $C J$, Salaniponi FM, Maher D, Nunn P: High mortality rates in tuberculosis patients in Zomba Hospital, Malawi, during 32 months of follow-up. Trans $R$ Soc Trop Med Hyg 2000, 94(3):305-309.

10. CT Kang'ombe ADH, Ito K, Clark T, Nyirenda TE, Aldis W, Nunn PP, Semba RD, Salaniponi FML: Long-term outcome in patients registered with tuberculosis in Zomba, Malawi: mortality at 7 years according to initial HIV status and type of TB. Int J Tuberc Lung Dis 2004, 8(7):829-836.

II. Cox HS, Morrow M, Deutschmann PW: Long term efficacy of DOTS regimens for tuberculosis: systematic review. $B m j$ 2008, 336(7642):484-487.

12. Lambert ML, Hasker E, Van Deun A, Roberfroid D, Boelaert M, Stuyft $P$ Van der: Recurrence in tuberculosis: relapse or reinfection? Lancet Infect Dis 2003, 3(5):282-287.

13. Buccheri S, Reljic R, Caccamo N, Meraviglia S, Ivanyi J, Salerno A, Dieli F: Prevention of the post-chemotherapy relapse of tuberculous infection by combined immunotherapy. Tuberculosis (Edinb) 2008, xxx:I-4.

14. Yassin MA, Datiko DG, Shargie EB: Ten-year experiences of the tuberculosis control programme in the southern region of Ethiopia. Int J Tuberc Lung Dis 2006, I0(10): I I66-II7I.

15. Datiko DG, Yassin MA, Chekol LT, Kabeto LE, Lindtjorn B: The rate of TB-HIV co-infection depends on the prevalence of HIV infection in a community. BMC Public Health 2008, 8:266.

16. Vijay S, Balasangameswara VH, Jagannatha PS, Saroja VN, Kumar P: Treatment outcome and two \& half years follow-up status of new smear positive patients treated under RNCTP. Indian J Tuberc 2004, 51:199-208.

17. Thomas A, Gopi PG, Santha T, Chandrasekaran V, Subramani R, Selvakumar N, Eusuff SI, Sadacharam K, Narayanan PR: Predictors of relapse among pulmonary tuberculosis patients treated in a DOTS programme in South India. Int $j$ Tuberc Lung Dis 2005, 9(5):556-561.
18. Vree M, Huong NT, Duong BD, Sy DN, Van LN, Hung NV, Co NV, Borgdorff MW, Cobelens FG: Survival and relapse rate of tuberculosis patients who successfully completed treatment in Vietnam. Int I Tuberc Lung Dis 2007, I I(4):392-397.

19. Abate G, Miorner H, Ahmed O, Hoffner SE: Drug resistance in Mycobacterium tuberculosis strains isolated from re-treatment cases of pulmonary tuberculosis in Ethiopia: susceptibility to first-line and alternative drugs. Int J Tuberc Lung Dis 1998, 2(7):580-584.

20. Lemma E, Niemi M, Lindtjorn B, Dubrie G: Bacteriological studies of tuberculosis in Sidamo Regional Hospital. Ethiop MedJ 1989, 27(3): 147- 149.

21. Tekle B, Mariam DH, Ali A: Defaulting from DOTS and its determinants in three districts of Arsi Zone in Ethiopia. Int J Tuberc Lung Dis 2002, 6(7):573-579.

\section{Pre-publication history}

The pre-publication history for this paper can be accessed here:

http://www.biomedcentral.com/1471-2458/9/348/pre pub

Publish with Bio Med Central and every scientist can read your work free of charge

"BioMed Central will be the most significant development for disseminating the results of biomedical research in our lifetime. "

Sir Paul Nurse, Cancer Research UK

Your research papers will be:

- available free of charge to the entire biomedical community

- peer reviewed and published immediately upon acceptance

- cited in PubMed and archived on PubMed Central

- yours - you keep the copyright 